\title{
Effect of progesterone on intracellular calcium in mESC-derived cardiomyocytes
}

Ieong Ung Hwang, Young-Kwon Choi, Hee Young Kang, Jin Yong An and Eui-Bae Jeung

\section{EP221: Cardiovascular Endocrinology}

\section{Abstract}

Sex steroid hormones effect on the early embryo-development and regulate the calcium signaling in cardiac muscle. Progesterone $(\mathrm{P} 4)$ has been reported to affect both blood pressure and other aspects of the cardiovascular system. To confirm the effect of P4 on early differentiation of mouse embryonic stem (mES) cells into cardiomyocytes, the hanging-drop method was performed to form embryoid bodies (EB). The mouse EBs (mEB) were suspended, attached onto 6 well plates and cultured in differentiation medium containing steroid-free FBS without LIF. P4 $(10 \mathrm{nM})$ was applied at two days after attachment and media were replaced every two days. To assess the differentiation into cardiomyocytes, the presence of mesoderm markers such as Branchyury and cardiac-specific marker genes such as $\mathrm{Tbx} 20$ and $\mathrm{Ctn} 1$ were confirmed. In addition, the expression of sex steroid hormone-receptors, including PR, ER and AR, was confirmed. Interestingly, mRNA expression of $\mathrm{AR}$ and $\mathrm{ER}$ increased time-dependently during differentiation into cardiomyocytes, while expression of PR exhibited the opposite pattern to that of the beating ratio. The beating ratio of the P4-treated group $(60.45 \pm 1.54 \%)$ decreased relative to that of the VE group $(92.17 \pm 2.98 \%)$ on day 12 . Based on this response, the expression of contraction-related genes and the intracellular $\mathrm{Ca} 2+$ level was investigated. The expression of contraction-related genes such as Ryr2, Cam2, Trpv2 and Mlck3 was decreased in the P4-treated group relative to the VE and RU486 group. The protein expression of TRPV2 in P4-treated group also decreased. Subsequent measurement of the intracellular $\mathrm{Ca} 2+$ level by confocal analysis revealed decreased level in the P4-treated group. Moreover, the beating frequency of the EB population was significantly lower in the P4-treated group. These results suggest that $\mathrm{P} 4$ induced a decrease in intracellular $\mathrm{Ca} 2+$ level with reduced expression of $\mathrm{Ca} 2+$ channel and regulatory proteins, thereby causing a decrease in contracting cardiomyocytes with low beating frequency.

\section{Results}

Correlation between steroid receptors and beating ratio during cardiac differentiation

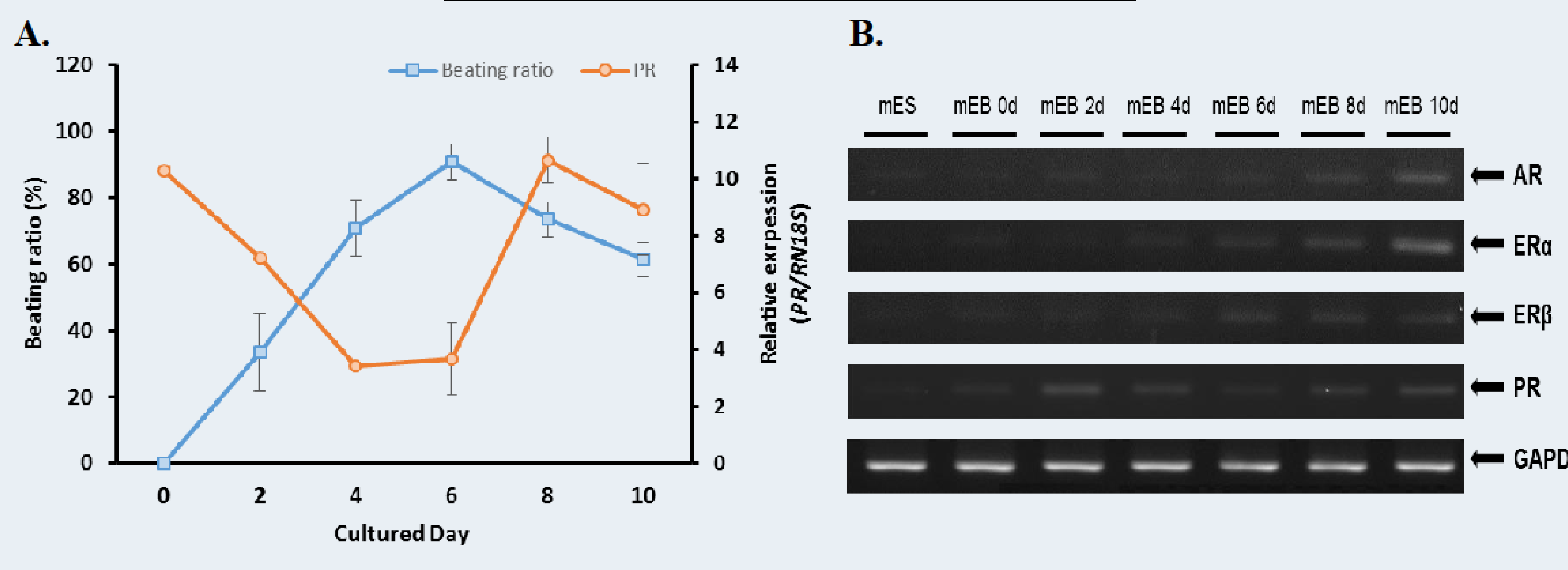

Fig 1 (A) The opposite pattern between pattern of beating ratio and mRNA expression of PR. (B) Time-dependently increased expression of sex steroid hormone-receptors in differentiated $\mathrm{mES}$ cells

\section{Expression of cardiac lineage markers}

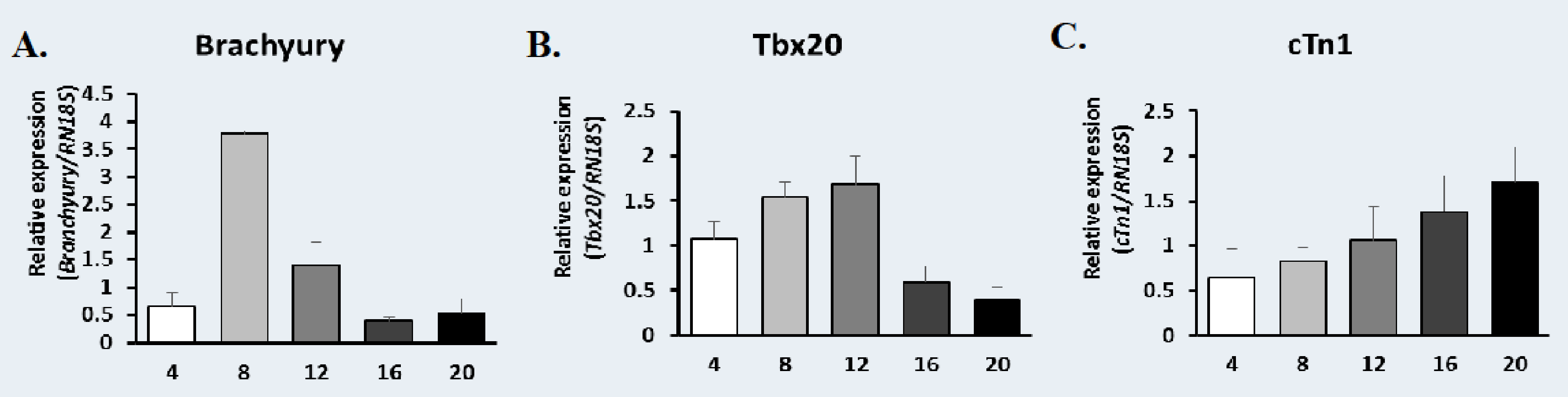

Fig 2 mRNA Expression of (A) Brachyury, (B) Tbx20 and (C) cTn1 during differentiation into cardiomyocytes.

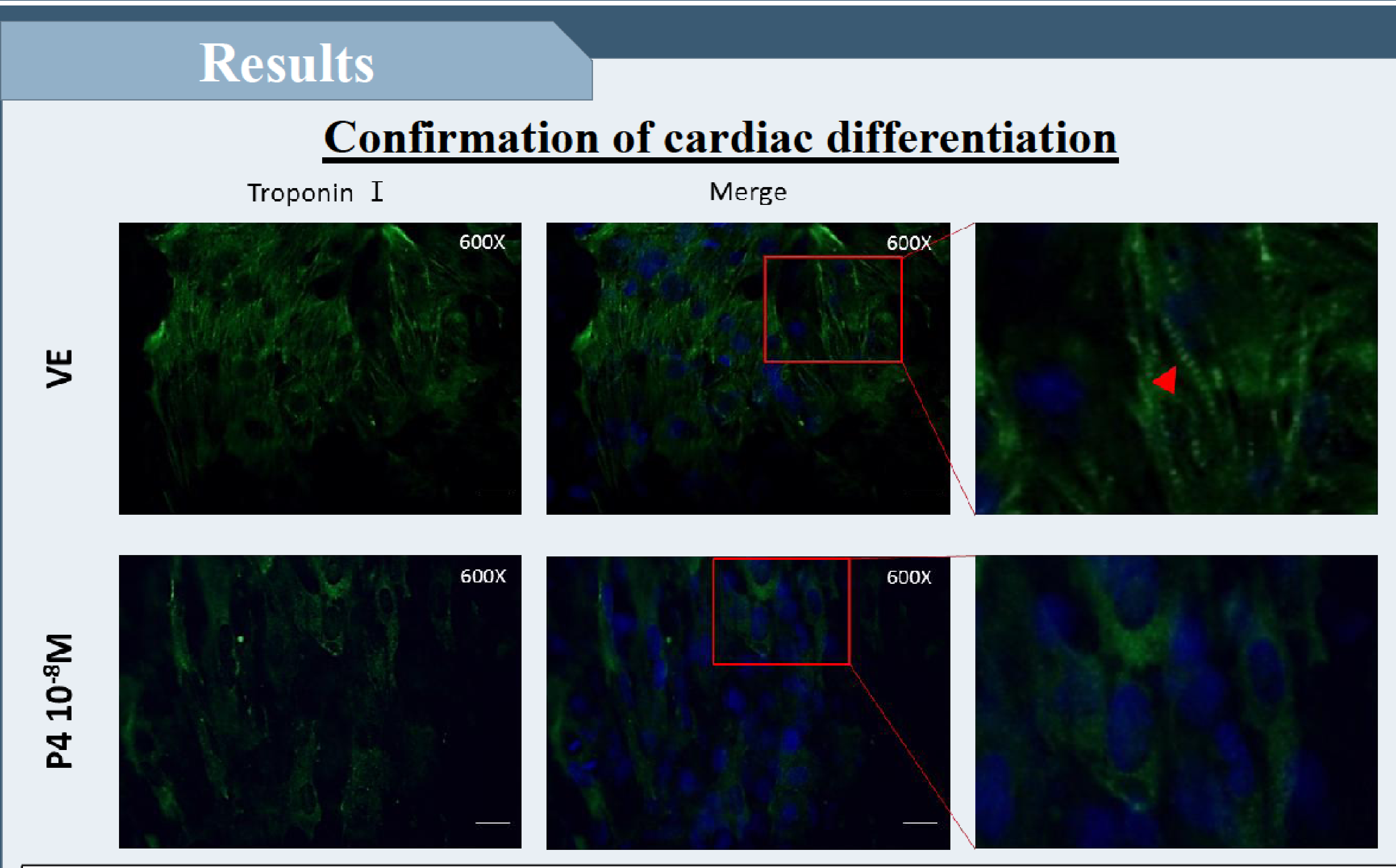

Fig 3 | Localization and expression of Troponin I confirmed on 12 days after attachment of $\mathrm{mEBs}$ by immunocytochemistry. Troponin I, green; nuclei stained with DAPI, blue; Scale bar $=20 \mu \mathrm{m}$.

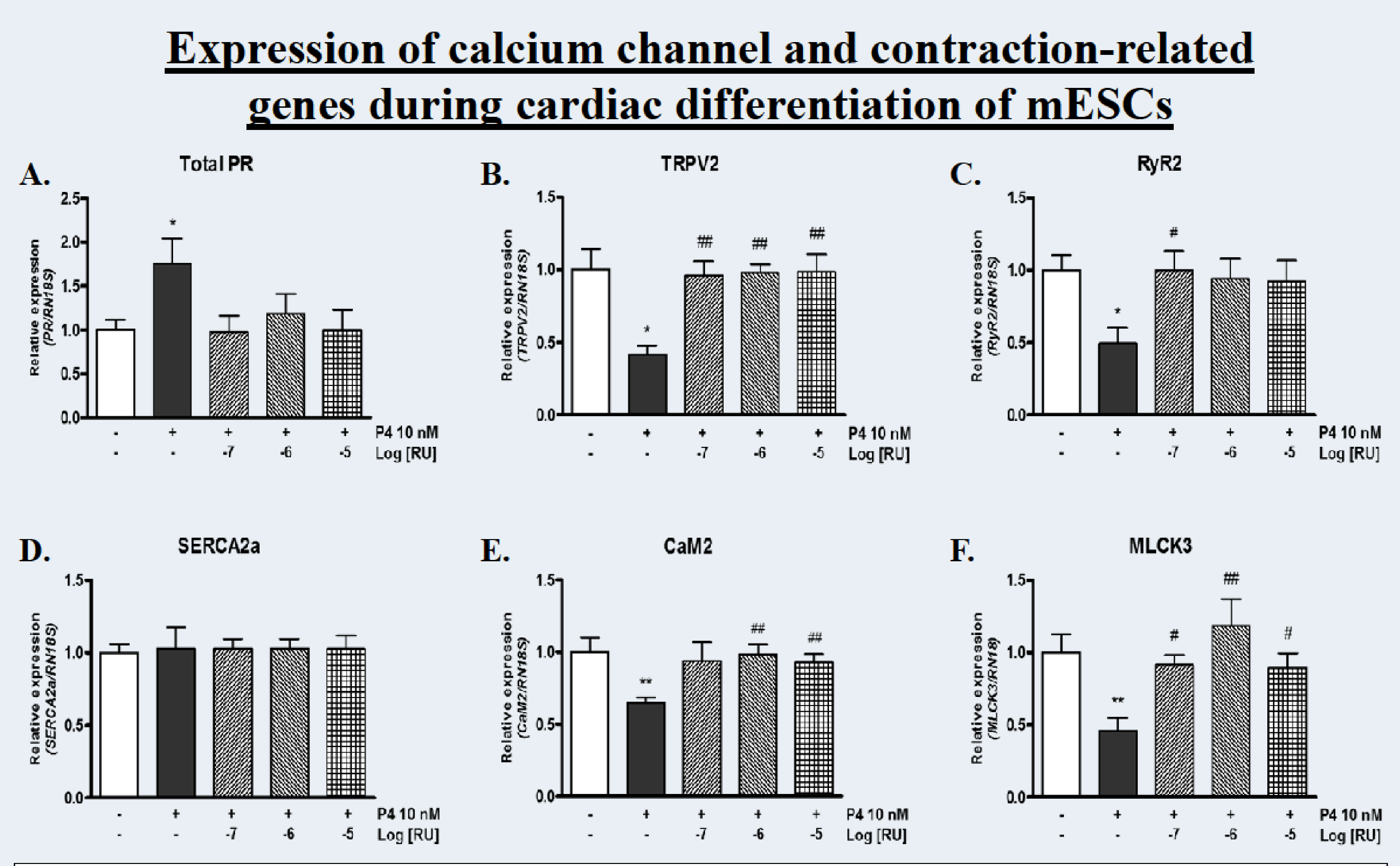

Fig 4 Differentiated cardiomyocytes were treated with VE (0.1\% DMSO), P4 $(10 \mathrm{nM})$ and different concentrations of RU486 $\left(10^{-7} \mathrm{M}, 10^{-6} \mathrm{M}, 10^{-5} \mathrm{M}\right)$. Quantifications of (A) PR, (B) TRPV2, (C) RyR2, (D) SERCA2a, (E) CaM2, and $(\mathrm{F}) \mathrm{MLCK} 3 .{ }^{*} P<0.05$ versus $\mathrm{VE},{ }^{\#} P<0.05$ versus $\mathrm{P} 410 \mathrm{nM}$.

\section{Conclusions}

\section{Effect of P4 on contraction pathway of differentiated mESCs}

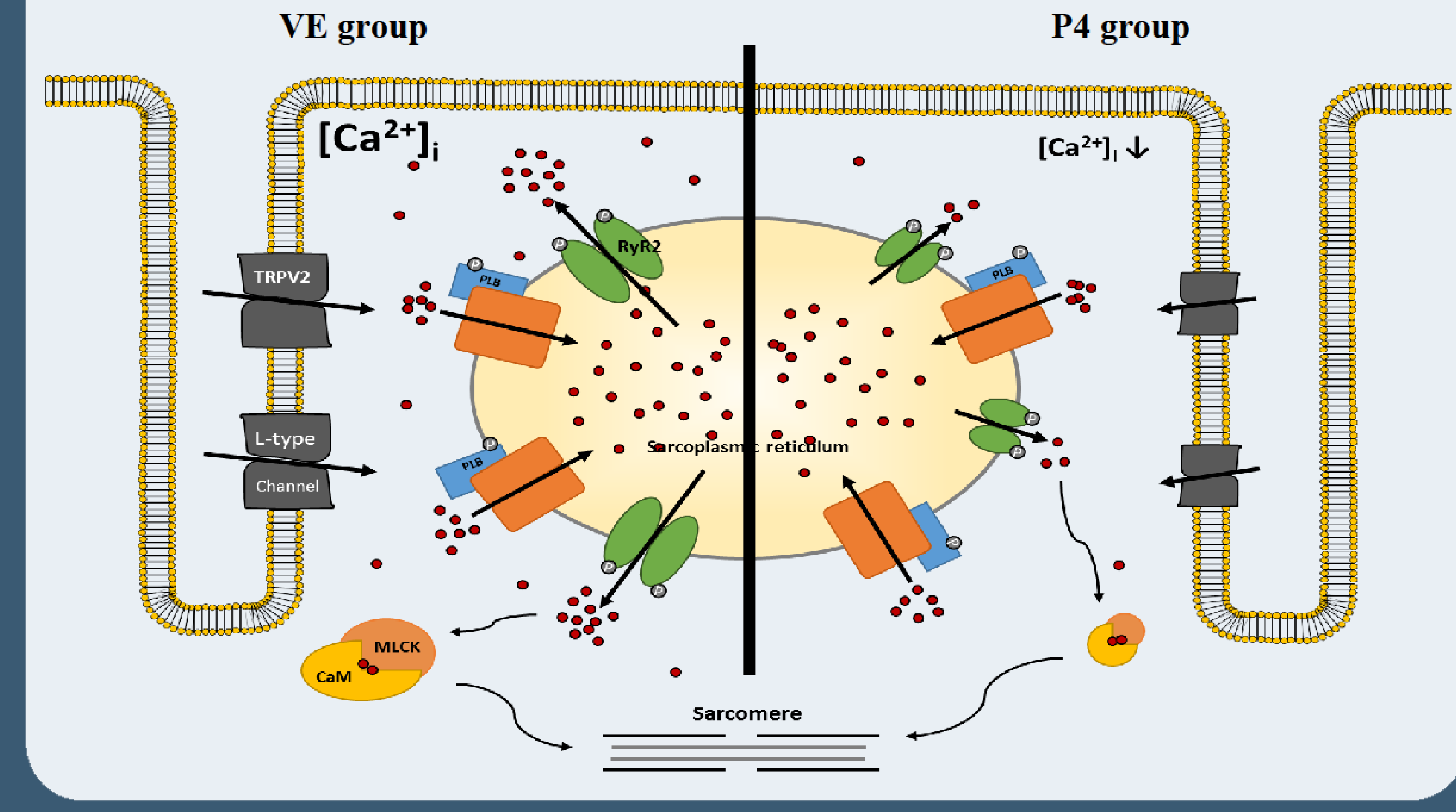

\section{References}

1] Arck P, Hansen PJ, Mulac Jericevic B, Piccinni MP, Szekeres-Bartho J. Progesterone during pregnancy: endocrine-immune cross talk in mammalian species and the role of stress. Am J Reprod Immunol. 2007;58:268-79 [2] Goldstein J, Sites CK, Toth MJ. Progesterone stimulates cardiac muscle protein synthesis via receptor-dependent thway. Fertil Steril 2004:82:430-6

3] Katanosaka Y, Iwasaki K, Ujihara Y, Takatsu S, Nishitsuji K, Kanagawa M, et al. TRPV2 is critical for the maintenance of cardiac structure and function in mice. Nat Commus. 2014;5:3932 